\title{
Comparative transcriptomic analysis of surf clams (Paphia undulate) infected with two strains of Vibrio spp. reveals the identity of key immune genes involved in host defense
}

\author{
Mingjia Yu ${ }^{1}$, Lin Zheng ${ }^{1}$, Xiaobo Wang ${ }^{1}$, Minfu Wu${ }^{1}$, Ming $\mathrm{Qi}^{1}$, Wandong $\mathrm{Fu}^{2}$ and Yang Zhang ${ }^{3,4^{*}}$
}

\begin{abstract}
Background: Vibrio spp. is the major infection-producing marine bacteria in commercially important bivalve Paphia undulata. The host resistance is the major determining factor for the development of pathogenesis. To explore defense mechanisms, researchers have focused primarily on the study of differential expression of individual or specific groups of host immune genes during pathogen-challenge.

Results: We compared the expression profile in the surf clams infected with avirulent $V$. alginolyticus and virulent $V$. parahaemolyticus to mark the possible molecular mechanisms of pathogenesis. Comparison of the differentially expressed genes between the two groups of Vibrio-infected clams revealed that the number of down-regulate genes in V. parahaemolyticus injected clams (1433) were significantly higher than the other group (169). Based on Gene Ontology classification, a large proportion of these down-regulate genes were found to be associated with cellular and molecular mechanisms for pathogen recognition, and immunity development thereby explaining the low survival rate for the $V$. parahaemolyticus-treated clams and suggesting a higher virulence of this bacterium towards the surf clams. Quantitative real-time PCR of 24 candidate genes related to immunity involving the JAKSTAT signaling pathway, complementary cascade, cytokine signaling pathway, oxidative stress, phagocytosis and apoptosis down regulated under $V$. parahaemolyticus infection, indicating compromised host defense. Furthermore, we could demonstrate a central role of JAK-STAT pathway in bacterial clearance. dsRNA mediated depletion of a clam STAT homolog gene results in dramatic increase in the infection by $V$. alginolyticus, a mildly pathogenic strain under control conditions.
\end{abstract}

Conclusions: The difference in gene expression profiles in surf clams treated with two Vibrio species with a differential pathogenicity to $P$. undulate and downstream molecular analysis could enlighten on the probable molecular mechanisms of the Vibrio pathogenesis and the virulence of $V$. parahaemolyticus in surf clams, which also benefits to develop new strategies for disease control in surf calm aquaculture.

Keywords: RNA-seq, Paphia undulate, Vibrio alginolyticus, Vibrio parahaemolyticus, Virulence

\footnotetext{
* Correspondence: yzhang@scsio.ac.cn

${ }^{3}$ CAS Key Laboratory of Tropical Marine Bio-resources and Ecology,

Guangdong Provincial Key Laboratory of Applied Marine Biology, South

China Sea Institute of Oceanology, Chinese Academy of Science, 164 West

Xingang Road, Guangzhou 510301, China

${ }^{4}$ Innovation Academy of South China Sea Ecology and Environmental

Engineering (ISEE), Chinese Academy of Sciences, Beijing 100864, China

Full list of author information is available at the end of the article
}

(C) The Author(s). 2019 Open Access This article is distributed under the terms of the Creative Commons Attribution 4.0 International License (http://creativecommons.org/licenses/by/4.0/), which permits unrestricted use, distribution, and reproduction in any medium, provided you give appropriate credit to the original author(s) and the source, provide a link to the Creative Commons license, and indicate if changes were made. The Creative Commons Public Domain Dedication waiver (http://creativecommons.org/publicdomain/zero/1.0/) applies to the data made available in this article, unless otherwise stated. 


\section{Background}

Bivalves are one of the earliest yet ubiquitous group of aquatic invertebrates with an estimated 10,000-20,000 living species. They are both economically and ecologically important with respect to food source, biomass and effects on communities. However, there is a steady progressive decline in the production of the bivalves following mass mortality among the farmed species due to marine microbial infections [1]. Till date, various species of the bacteria Vibrio and the protozoa Perkinsus have been identified as the major disease-producing pathogens affecting the development and survival of clams and diminishing the meat quality and thereby the price of the products [2]. The sedentary and filter-feeding habits among the bivalve mollusks lead to the accumulation of microorganisms (bacteria, fungi and parasites). These microorganisms besides being the source of nourishment also lead to the development of immune challenge in the mollusks [3].

The host resistance is the major determining factor for the development of pathogenesis. The defense mechanism in mollusks mainly relies on the effectors of innate immunity, which is mediated by circulating competent cells- referred to as hemocytes, and highly diversified humoral antimicrobial factors. Both these cellular and humoral components work in a synergistic way to initiate the recognition, segregation and ultimately elimination of pathogens and other non-self entities $[4,5]$. The cellular response of innate immunity consists of three principle steps: (1) identification of pathogen-associated molecular patterns [PAMPs] by pattern recognition receptors [PRRs]; (2) activation of the regulatory pathways and (3) production of immune effectors to modulate cellular phagocytosis and to produce molecular effectors like antimicrobial peptides [AMPs] [6, 7]. In clams, phagocytosis and cytotoxicity are the two mechanisms for this cellular immunity; the latter involving the release of lysozymes, anti-microbial peptides, superoxide anion and hydrogen peroxide. On the other hand, humoral components include the lectin in addition to lysozymes and anti-microbial peptides [8]. Besides immunity, the hemocytes have various known functions including digestion, transport of nutrients, formation and mending of the shell, repair of wounds, excretion and internal defense [9]. Therefore, the molecular mechanisms for defense and other cellular and metabolic processes occurring in the hemocytes of clams during pathogen invasion are investigated to understand the host-pathogen interaction with a view to design therapeutic targets.

To explore defense mechanisms, researchers hitherto have focused primarily on the study of differential expression of individual or specific groups of host immune genes during pathogen-challenge. Recent application of high-throughput next generation sequencing technologies involving direct sequencing of transcripts (RNA-seq) are providing extensive information about host-microbe interactions at the transcriptional level including global gene expression and novel gene discovery [10-12]. The Solexa/ Illumina and 454/Roche NGS technologies have been revolutionary for understanding the rich transcriptomes of the mollusks [13]. Due to its relatively low cost and good results obtained in different organisms, the Illumina RNASeq technology paired-end is a promising tool to study the clam immune system as well $[11,14,15]$.

The surf clams are the bivalves supporting the largest proportion of the shellfishery market in China. In spite of it economic importance, the underlying molecular mechanism of surf clam defense towards Vibrio-infections remains largely unexplored. There are only two previous studies on the expression analyses of defense-related genes in surf clams (Mesodesma donacium) during Vibrio spp. ( $V$. anguillarum)-challenge $[16,17]$. In order to elucidate the immune mechanism associated with Vibrio-infection in surf calms, we utilized Illumina RNA-seq to score gene expression changes in $P$. undulate infected with two Vibrio pathogens$V$. parahaemolyticus and $V$. alginolyticus. Of these two strains, $V$. parahaemolyticus was found to be more virulent than $V$. alginolyticus, as evidenced by the survival rate of $P$. undulate post pathogenic injection. Thus the comparison of the transcriptome of $P$. undulate infected with these two Vibrio strains could help us identify specific immune genes contributing to host resistance and molecular mechanism underlying the pathogenesis of marine molusks.

\section{Results}

\section{$V$. parahaemolyticus is pathogenic towards $P$. undulata}

To test the pathogenicity of the two Vibrio species, $V$. parahaemolyticus and $V$. alginolyticus towards surf clam Paphia undulate, the survival rate of the infected clams were measures at $24 \mathrm{~h}, 36 \mathrm{~h}, 48 \mathrm{~h}, 60 \mathrm{~h}$ and $72 \mathrm{~h}$ postinjection. A clear difference in the survivality was observed between clams infected with $V$. parahaemolyticus (VP) and the ones infected with $V$. alginolyticus (VA) in comparison to the controls (C) (Fig. 1). The survival rate of VA group was mostly comparable to the uninfected control group, $\mathrm{C}$ till $48 \mathrm{~h}$ post infection. At $72 \mathrm{~h}$ postinfection only a moderate decrease to $84.6 \%$ survival was noted in VA. In contrast, among VP group, the rate of survival of clams indicated a steep decline at $24 \mathrm{~h}$ $(87.2 \%)$ and $48 \mathrm{~h}(65.3 \%)$ post-infection. At $72 \mathrm{~h}$ postinfection the percentage of surviving clams for VP decreased to $52.6 \%$; thereby indicating a higher pathogenicity of $V$. parahaemolyticus towards surf clams.

\section{Transcriptomic analysis of Vibrio infected surf clams, $P$. undulata}

To gain better insight into mechanism of Vibrio mediated infection of surf clam $P$. undulate, high-throughput 


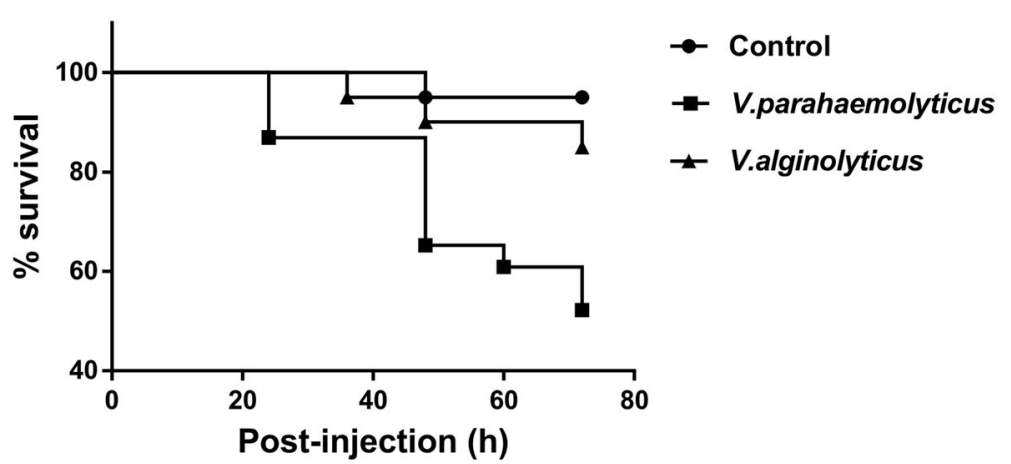

Fig. 1 Comparison of rate of survival of surf clams treated with V. alginolyticus and V. parahaemolyticus with the controls (treated with PBS) from $24 \mathrm{~h}$ to $72 \mathrm{~h}$ post-challenge

RNA-seq based transcriptomic analysis was performed. cDNA libraries were prepared for the $V$. parahaemolyticus and $V$. alginolyticus infected clams (VP and VA, respectively) and were sequenced using Illumina platform. All three libraries were assembled into annotated 74,433 sequences, which were used for references sequence for quantification analysis. The total mapped reads were 14, $651,562,13,544,017$ and 14,529,523 for VP, VA and C groups respectively (Table 1 ). The percentage of clean reads in each library ranged from 52.04 to $55.11 \%$ of the total reads. The read summary of the sequences are provided in Table 1. Based on false discovery rate (FDR) $\leq$ $0.001,766$ and 3550 candidates were obtained from the VA and VP libraries, respectively. Using a cut-off criterion of Log10 fold change $\geq$ or $\leq 1,383$ and 1775 DEG were identified for VA and VP, respectively. Interestingly, we observed that a striking 1346 transcripts were found to be exclusively down-regulated in the VP group (Fig. 2a). Compared to the VA group the number of exclusive genes down-regulated in VP was much higher. Only 156 DEGs were shared between the two genesets, of which 69 and 87 were up and down-regulated respectively (Fig. 2a). The scatter plots showing the distribution of up and down regulated genes in VA and VP are provided with represented as log of RPKM values. The distribution of up-regulated and down-regulated genes in VA and VP with respect to control $(\mathrm{C})$ is given by normalizing to RPKM values in Fig. $2 b$ and $c$ respectively.
Functional analysis of genes affected by Vibrio infection In order to get a better understanding about the Vibrio infection mechanism, a functional analysis of the DEGs were performed. Gene Ontology (GO) analysis showed that the DEGs were clustered into distinct groups (Fig. 3a and b). Of the 383 for VA and 1619 for VP had a GO ID and could be categorized into 55 functional groups. Strikingly, the most difference was that in contrast to large numbers of mapped up-regulated genes in VA and most of the mapped VP genes were downregulated (Fig. 3b). For biological process category, the most abundant genes were identified for cellular process (110 DEGs for VP), metabolic process (90 DEGs for VP) and single-organism process (80 DEGs for VP). For cellular component category, the most abundant genes were identified for cell (85 DEGs for $\mathrm{VP}$ ), cell parts (82 DEGs for VP) and organelle (75 DEGs for VP). For molecular function category, the most abundant genes were identified for binding (75 DEGs for VP), catalytic activity (84 DEGs for VP) and metabolic processes (98 DEGs for VP). Similar functional categories were also found to be significantly effected in VA geneset as well. Additionally, detailed analysis revealed that transcript assignment to $\mathrm{GO}$ terms identified genes related to pathogen recognition, binding and innate immunity of surf clams which were all down regulated in VP but were either up-regulated or did not show any variation in expression in VA. These include immune system process (2 DEGs);

Table 1 Summary statistics of the transcriptome assembled

\begin{tabular}{lllllllll}
\hline Sample ID & Raw reads & $\begin{array}{l}\text { Total base } \\
\text { pairs }\end{array}$ & $\begin{array}{l}\text { Total Mapped } \\
\text { Reads }\end{array}$ & Perfect Match & $\begin{array}{l}<=2 \text { bp } \\
\text { Mismatch }\end{array}$ & Unique Match & $\begin{array}{l}\text { Multi-position } \\
\text { Match }\end{array}$ & $\begin{array}{l}\text { Total Unmapped } \\
\text { Reads }\end{array}$ \\
\hline C & 27921778 & 3490222250 & 14529523 & 9978734 & 4550789 & 13087865 & 1441658 & 13392255 \\
VA & 25931856 & 3241482000 & 13544017 & 9266974 & 4277043 & 12068700 & 1475317 & 12387839 \\
VP & 26587838 & 3323479750 & 14651562 & 10114803 & 4536759 & 13205013 & 1446549 & 11936276 \\
\hline
\end{tabular}



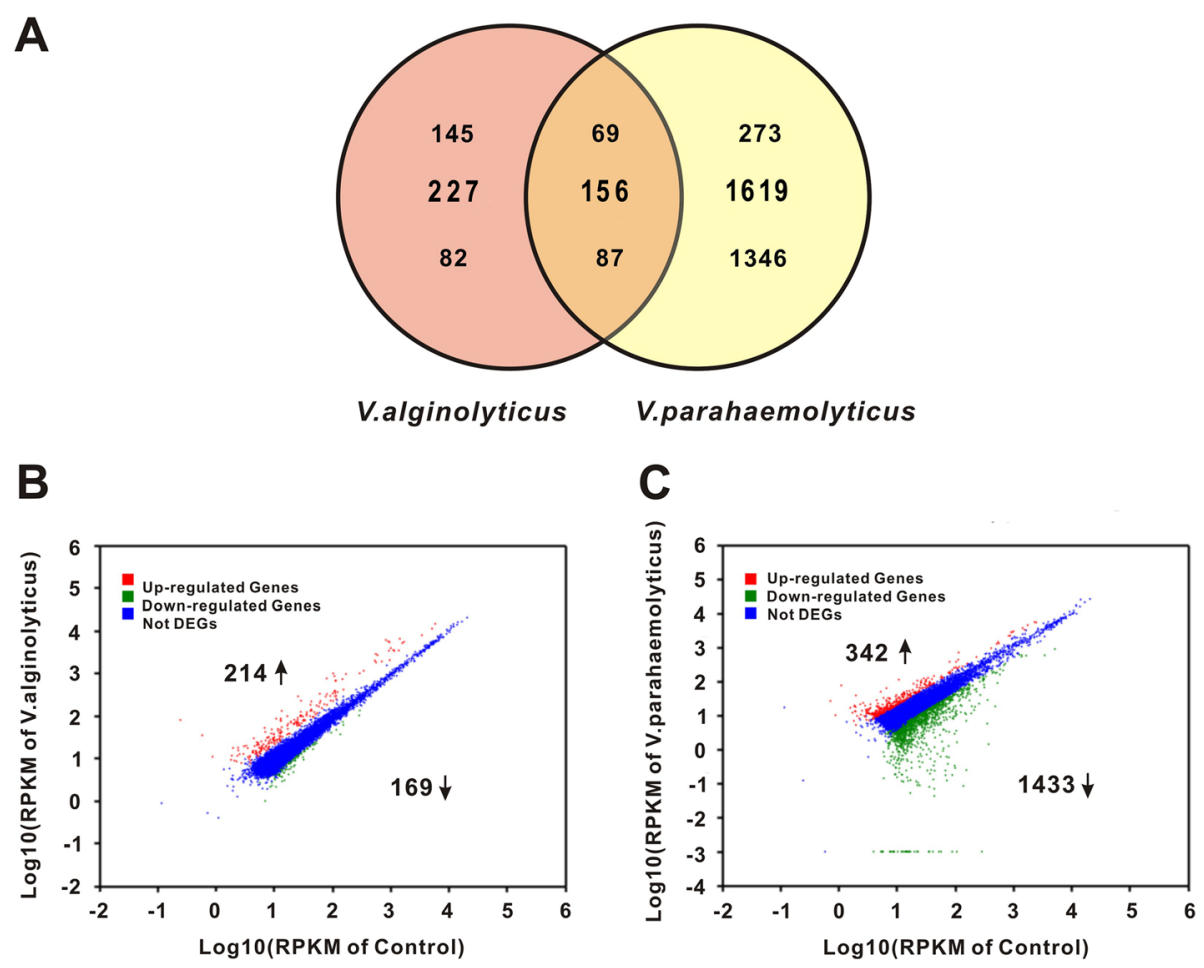

Fig. 2 Comparative distribution of differentially and non-differentially expressed genes (DEGs and non-DEGs) in the surf clams treated with $V$. alginolyticus and $V$. parahaemolyticus. a Venn diagram representing the number of both common and exclusive DEGs and non-DEGs between the surf clams treated with $V$. alginolyticus and $V$. parahaemolyticus respectively. The numericals in the upper row, middle row and the lower row represent the numbers of up-regulated, non-DEGs and down-regulated genes respectively. $\mathbf{b} \& \mathbf{c}$ Normalized distribution of DEGs and non-DEGs obtained from V. alginolyticus (b) and V. parahaemolyticus (c) infected surf clam libraries

response to stimulus (18 DEGs); macromolecular complex (15 DEGs); membrane (30 DEGs) and membrane part (18 DEGs). All the genes involved in establishment of localization (3DEGs for VA and 10 for VP) and localization (3DEGs for VA and 10 for VP) were found to be up-regulated in VA and down-regulated in VP libraries. In summary, these terms account for a large fraction of the overall assignments in the transcriptome of the surf clam (Table 2).

\section{V. parahaemolyticus infection results in the suppression of key immune genes in the clam $P$. undulata}

Repression of large number of immune genes in P.undulata haemocytes infected with $V$. parahaemolyticus led us to undertake a through qRT-PCR based analysis of candidate immune genes. Twenty four innate immunity or immunity related genes involved in anti-oxidation, complement cascade, JAK-STAT signaling, pattern recognition, apoptosis, phagosome and oxidative phosphorylation were selected for the analysis (Table 3). Strikingly, all the 24 gene assayed showed a reduced expression in the VP group as compared to the VA, and the repression was particularly prominent for $\mathrm{C} 1 \mathrm{q} 3$ of complement cascade, STAT of JAK-STAT signaling pathway, MR2 and BGRP pattern recognition proteins, Caspase 3 of apoptotic pathway and Rho-J and Rab-5C involved in phagosome formation. Additionally, all the tested members of oxidative phosphorylation- CYTB, COX3, COX1, ND5 and ND1 were drastically repressed in VP (Fig. 4). Additionally, these qRT-PCR analyses validate our Illumina RNA-seq results to a large extent. The correlation of the fold change of DEGs obtained by Illumina RNA-seq and qRT-PCR was analyzed by scattered plot (Fig. 5). The pattern of fold change of DEGs observed from Illuminia RNA-seq well corroborated with that from qRT-PCR $\left(\mathrm{R}^{2}=0.948\right.$ and $p$ value $<$ 0.001 ). The values were mostly clustered between 0.5 and 1 while very few remain scattered between the ranges 2 to 4 for both the dataset. Therefore, qRT-PCR data supported the sequencing results and provided data about the suitability of using the Illumina sequencing approach for de novo assembly of the surf clam hemocytes transcriptome without a reference genome.

JAK-STAT pathway plays a key role in bacterial clearance To further investigate the involvement of JAK-STAT pathway in successful establishment of Vibrio infection in surf clams, we utilized JAK-STAT pathway inhibitors- 


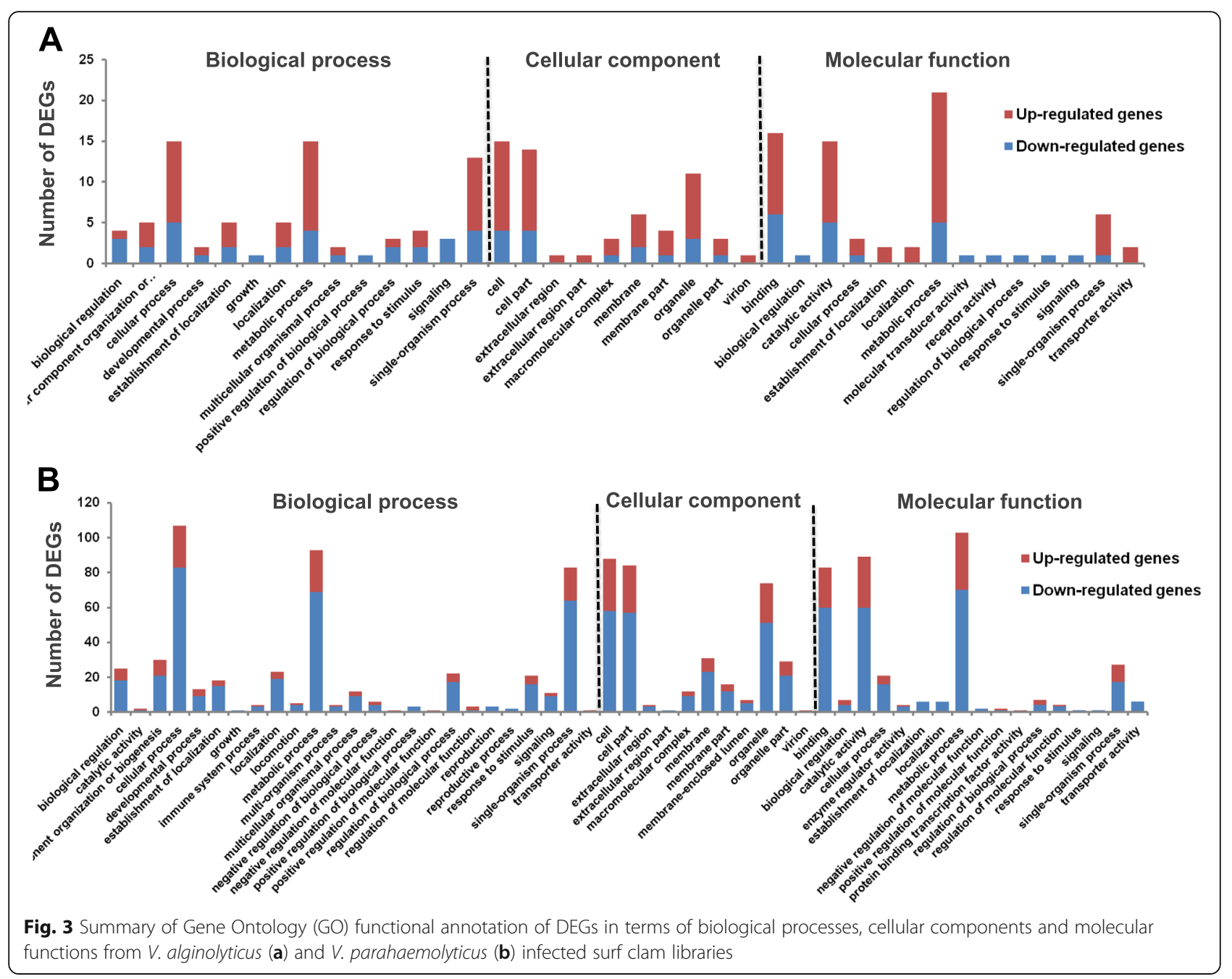

methotrexate and ruxolitinib. We investigated infection induced apoptosis in JAK/STAT pathway inhibitor treated surf clams. Suppression of JAK/STAT pathway induced apoptosis in VA infected clams, and the observed apoptotic index was significantly higher than DMSO treated controls (Fig. 6a). Inhibitor treatment did not induce apoptosis in uninfected controls, indicating that the observed increase is due to the successful establishment of VA infection (Fig. 6a). VP, on the other hand could induce apoptosis in DMSO treated controls, which was moderately enhanced under JAK/STAT pathway inhibitor treatment (Fig. 6a). The apoptotic index of VA and VP infected inhibitor treated clams were mostly comparable (Fig. 6a). Additionally, we also monitored the effect of JAK/STAT pathway on ability of bacterial clearance in surf clams. As expected, the bacterial count in VA infected and control (DMSO treated) clams were low in comparison to VP infected ones presumably due to the lower virulence of VA. Interestingly, treatment with either methotrexate or ruxolithinib of the clams leads to a significant increase in bacterial count under
VA infection (Fig. $6 \mathrm{~b}$ and c). Since VA is mildly virulent to $P$. undulate, the above results indicate a central role of JAK/STAT pathway against Vibrio defense. Moderate changes in the bacterial count were also noted in VP infected, inhibitor treated clams. Therefore, considering all these evidences, it can be concluded that in surf clam $P$. undulate JAK-STAT pathway plays a crucial role in bacterial clearance; inhibition of which results in establishment of successful infections in clams by a virulent VA strains as well.

\section{Identification of putative STAT gene involved in clam defense}

Based on our transcriptome mapping, four putative genesunigene0046025, unigene0045192, unigene0039277 and unigene0070069, were annotated to the STAT protein in P. undulate. To elucidate their possible role in Vibrio infection, we performed dsRNA mediated knockdown of the four genes mentioned above in surf clam. The efficiency and specificity of the target gene knockdowns were tested by qPCR (Fig. 7). Clams treated with double-stranded 
Table 2 Classification of the transcriptome according to GO terms

\begin{tabular}{|c|c|c|c|c|}
\hline \multirow[t]{2}{*}{ GO accession } & \multirow[t]{2}{*}{ GO term } & \multirow[t]{2}{*}{ Functional category } & \multicolumn{2}{|c|}{ No of DEGS } \\
\hline & & & $\mathrm{VP}$ & VA \\
\hline GO:0009987 & Cellular process & Biological process & 110 & 15 \\
\hline GO:0008152 & Metabolic process & & 90 & 15 \\
\hline GO:0022413 & Single organism process & & 80 & 13 \\
\hline GO:0002376 & Immune system process & & 2 & 0 \\
\hline GO:0005623 & Cell & Cellular component & 85 & 15 \\
\hline GO:0044464 & Cell parts & & 82 & 13 \\
\hline GO:0043226 & Organelle & & 75 & 12 \\
\hline GO:0032991 & Macromolecular complex & & 15 & 3 \\
\hline GO:0016020 & Membrane & & 30 & 5 \\
\hline GO:0044425 & Membrane part & & 18 & 3 \\
\hline GO:0005488 & Binding & Molecular function & 75 & 17 \\
\hline GO:0003824 & Catalytic activity & & 84 & 16 \\
\hline GO:0008152 & Metabolic process & & 98 & 20 \\
\hline GO:0050896 & Response to stimulus & & 18 & 1 \\
\hline GO:0051234 & Establishment of localization & & 10 & 3 \\
\hline GO:0051179 & Localization & & 10 & 3 \\
\hline GO:0005215 & Transporter activity & & 5 & 3 \\
\hline GO:0022413 & Single organism process & & 20 & 7 \\
\hline
\end{tabular}

RNA against green fluorescent protein (GFP) were used as controls. Putative STAT gene depleted clams were then infected with either $V$. alginolyticus or $V$. parahymolyticus (Fig. 7a). To access infection levels, apoptosis index were measured under various treatment conditions. In the control (dsGFP), VA infection results in an apoptosis index similar to uninfected calms, while a significantly higher apoptosis was observed under VP infection reflecting on the higher virulence of VP, mentioned above (Fig. 7b). Interestingly, knockdown of unigene0039277 results in a significant increase in the VA infection apoptosis index, which is noticeably higher than uninfected controls. This result suggests a key role of the clam unigene0039277 in combating Vibrio infection, the loss of which results in higher virulence of mostly nonpathogenic VA. A significant but lesser increase in the apoptotic index was observed under VP infection in unigene0039277 depleted clams as well (Fig. 7b). Additionally, unigene0039277 being mapped to clam STAT protein, the above experiment strongly support our previous results on the central role of JAK/STAT pathway in clam defense against bacterial infection. However, knockdown of other unigenes mapped to STAT does not play a noteworthy role against Vibrio attack, as evidenced by the similarity in apoptosis index derived infection profile with the control.
STAT transcriptionally regulates the expression of other immune genes in $P$. undulate

To further investigate the role of unigene0039277, we tested the expression of key defense related genesglutathione-S-transferase (GST), inhibitor of apoptosis (IAP) and tumor necrosis factor (TNF) in unigene0039277 depleted clams. GSTs are proteins which help in cellular detoxification by conjugating the toxins with glutathione $(\mathrm{GSH})$, increase their solubility and thereby aiding to the easy removal of the toxins from the cells $[20,21]$. On the other hand, IAPs are the class of proteins that suppress host cell death by inhibiting caspases during infection [22]. In addition, IAP is related to signal transduction pathways used by TNF-receptors. This TNF plays role in systemic inflammation and is a cytokine involved during acute phase infection by regulating the immune cells [23]. TNF stimulates phagocytosis and promotes the expression of adhesion molecules on endothelial cells; thereby helping in the migration of neutrophils. Our qRT-PCR analysis revealed that the basal expression of all the three genes tested were compromised in unigene0039277 depleted uninfected clams (Fig. 8). Specifically, the relative expression for GST, IAP and TNF was found to be $43.8,32.5$ and $41.2 \%$, respectively of the dsGFP controls (normalized to be at $100 \%$ level) (Fig. 8). Thus JAK-STAT pathway, particularly 


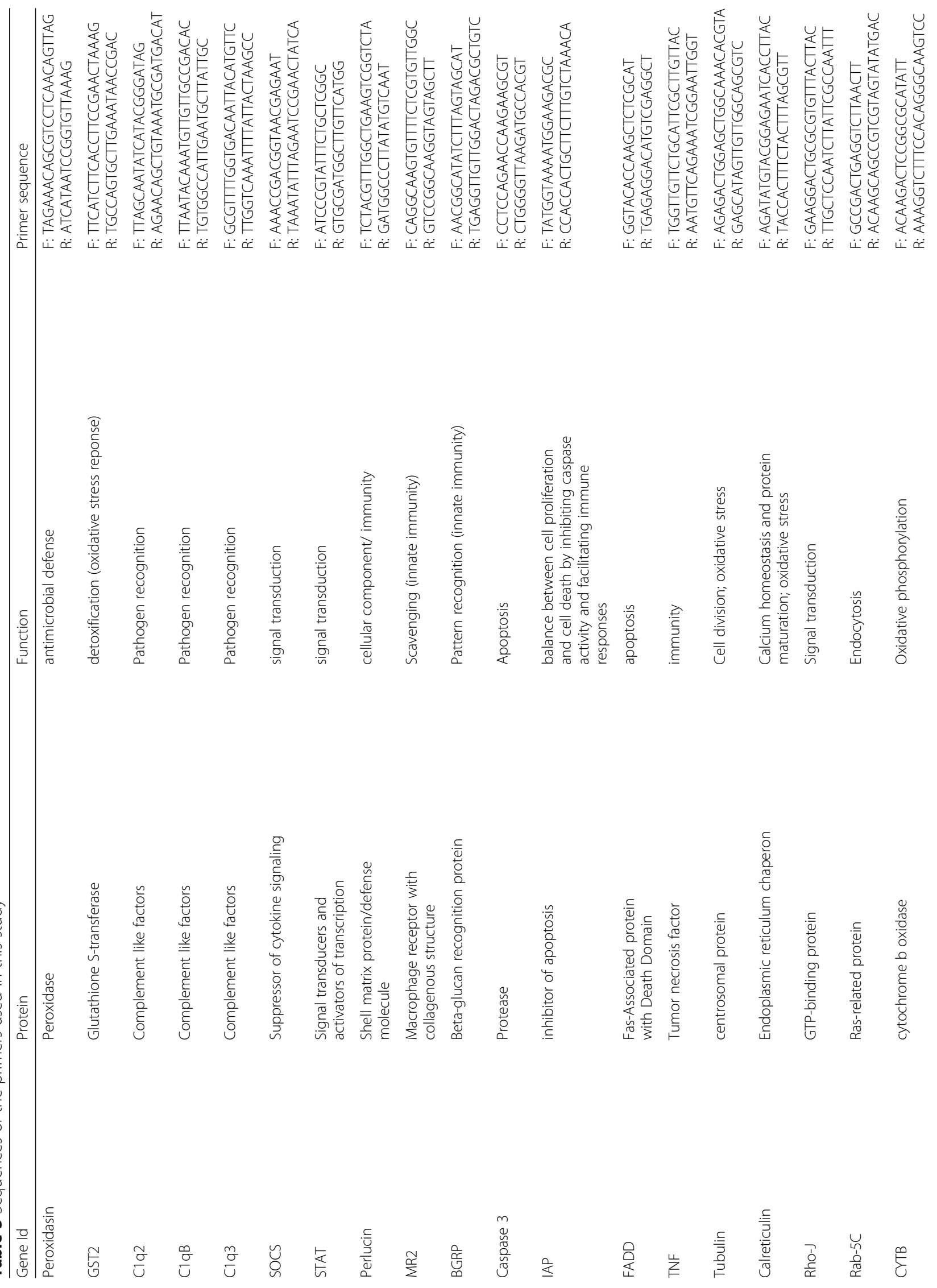




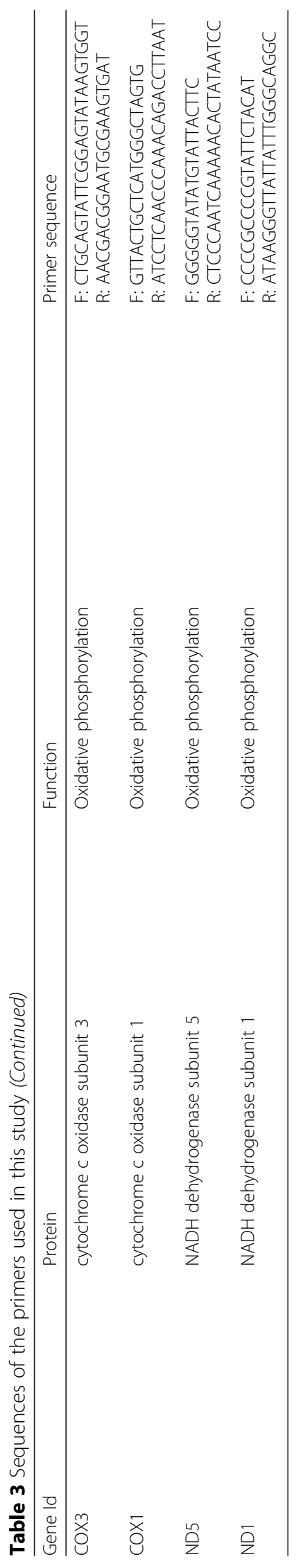




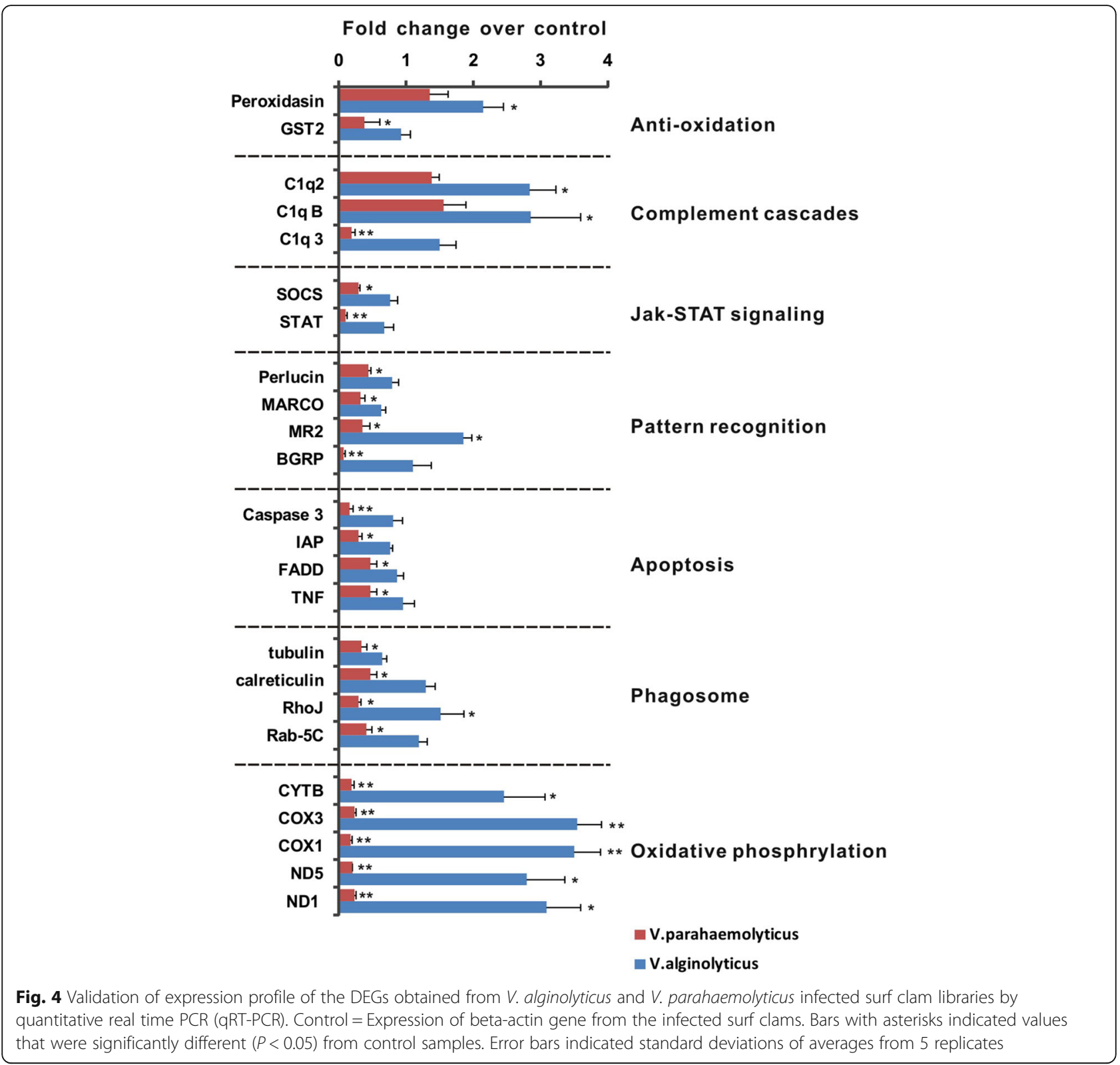

unigene0039277, regulates the transcription of key immune genes in clams.

\section{STAT gene homolog imparts resistance against Vibrio attack}

Next, we investigated the effect of unigene 0039277 on the survival of surf clams under VA and VP infection. dsGFP injected clams were used as controls and uninfected dsGFP clam showed a near 100\% survival rate at about $70 \mathrm{~h}$ post infection (Fig. 9). The observed results for dsGFP are similar to that described previously for untreated clams (Fig. 1). Uninfected unigene0039277 depleted clams showed a survival rate slightly lower $(96.6 \%$ at $72 \mathrm{~h}$ post injection) than dsGFP controls. However, under VA infection, prominent differences were observed in survival rates between dsGFP $(91.7 \%$ at $72 \mathrm{~h}$ post injection) and unigene0039277 depleted $(67.4 \%$ at $72 \mathrm{~h}$ post injection) groups, with a drop of nearly $24.3 \%$ (Fig. 9). Thus, it can be assumed that the loss of this key gene unigene 0039277 transforms the mildly pathogenic VA strain to a virulent one. Loss of unigene0039277 also impacts the VP infection and the survival rate drops even further compared to VP infected dsGFP injected controls (Fig. 9). Taken together, our results suggest a key role for the STAT homolog unigene0039277 in resistance against Vibrio infection in P. undulate, and presumable the virulent strain $V$. parahaemolyticus establishes infection by suppressing this gene by utilizing a 


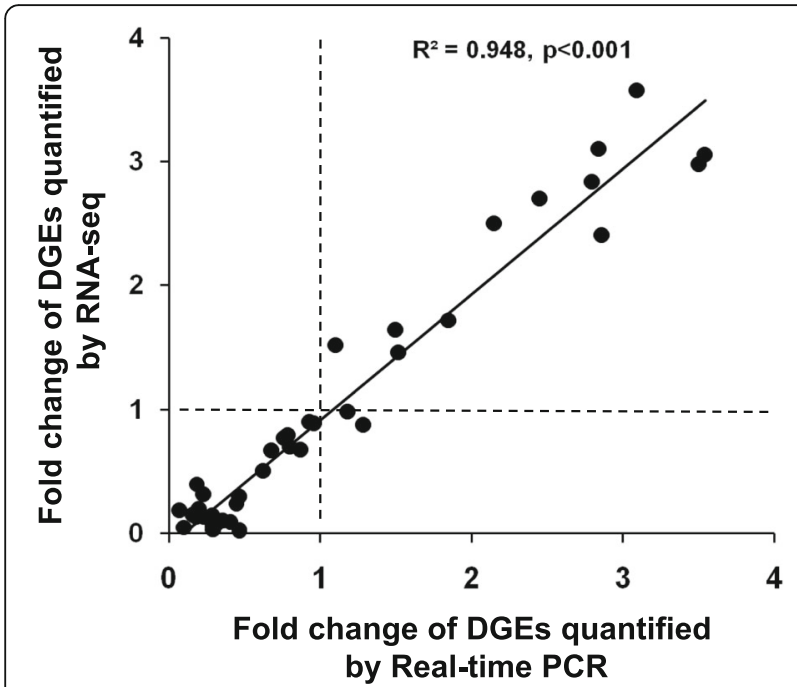

Fig. 5 Scattered plot analysis of comparing expression correlation of candidate DEGs through RNA-sequencing on Illumina platform and qRT-PCR. Each point represents one DEG with paired expression value. $X$-axis and $Y$-axis indicates the expression value that quantified by Real-time PCR and RNA-seq, respectively yet unknown mechanism. The suppression of this gene is presumably a key step in the establishment of the virulent strain $V$. parahaemolyticus.

\section{Discussion}

Aiming to elucidate the mechanism of Vibrio infection in surf clams, RNA-seq based transcriptomic analysis was performed with the hemocyte from infected $P$. undulate. Two strains of Vibrio were used, one being less pathogenic than the other. While $V$. parahaemolyticus infection resulted in a dramatic reduction in the survival of surf clams, the $V$. alginolyticus infected clams could overcome the bacterial challenge and had a survival curve similar to the controls. This clearly indicated the differential pathogenicity of these two Vibrio strains, and established $V$. parahaemolyticus as a more virulent strain than $V$. alginolyticus. The comparison of these two transcriptomes and follow up qRT-PCR experiments revealed the identity of certain genes which might be involved in the process of pathogen establishment. Comparison of the two transcriptomes revealed that the expressions of a much higher number of genes were affected by $V$. parahaemolyticus infection in contrast to $V$.
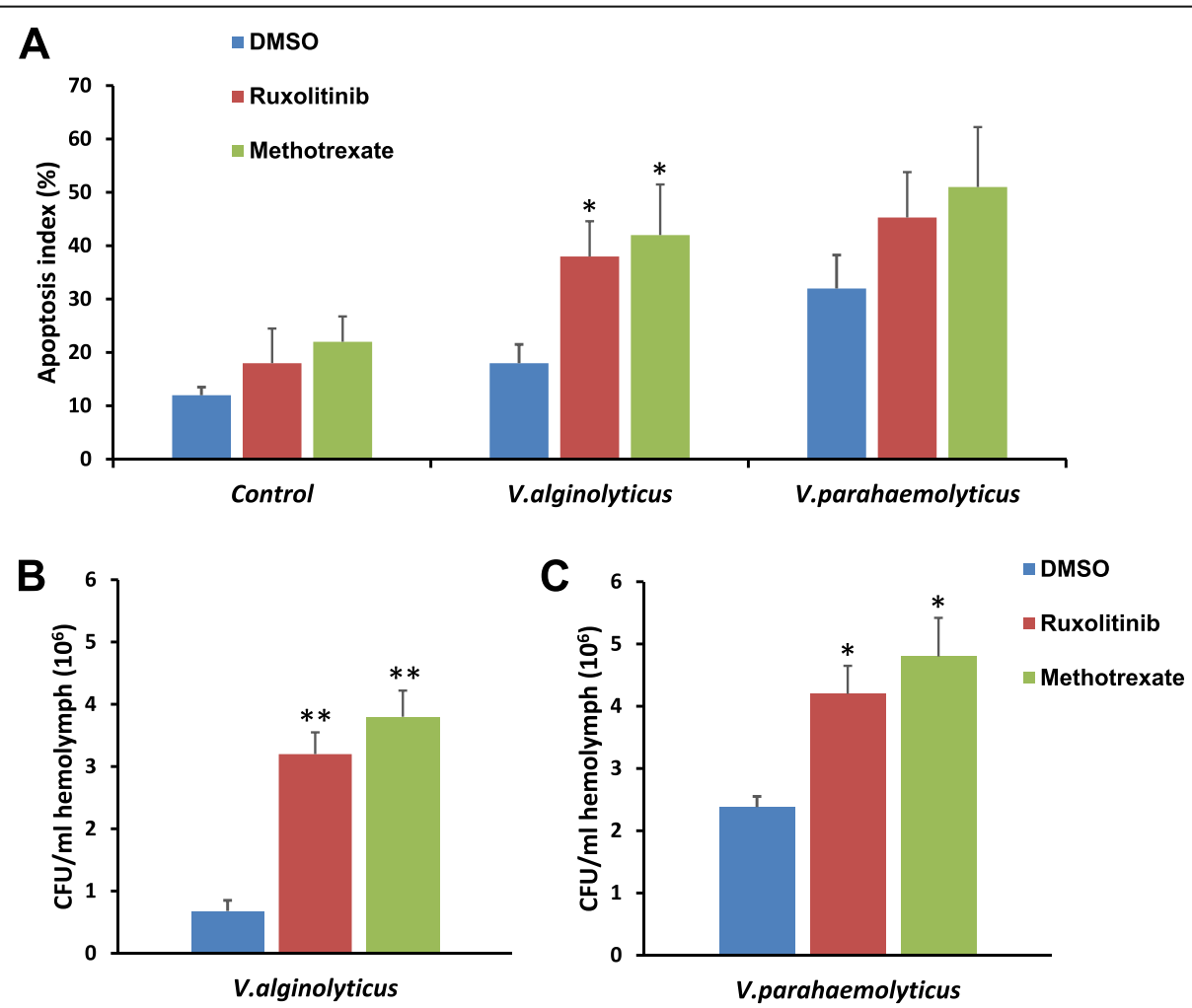

Fig. 6 JAK-STAT pathway plays a key role in bacterial clearance. a \& b Bacterial count (Colony forming units, CFU) in V.alginolyticus (a) and V.parahemolyticus (b) infected surf clams treated with JAK/STAT pathway inhibitors Ruxolitinib and Methotrexate. DMSO treatment was used as controls. $N=3$. c Apoptosis index (\%) in V.alginolyticus and V.parahemolyticus infected surf clams treated with JAK/STAT pathway inhibitors Ruxolitinib and Methotrexate. DMSO treatment was used as controls. The infected clams were compared with uninfected controls. $N=5$ 

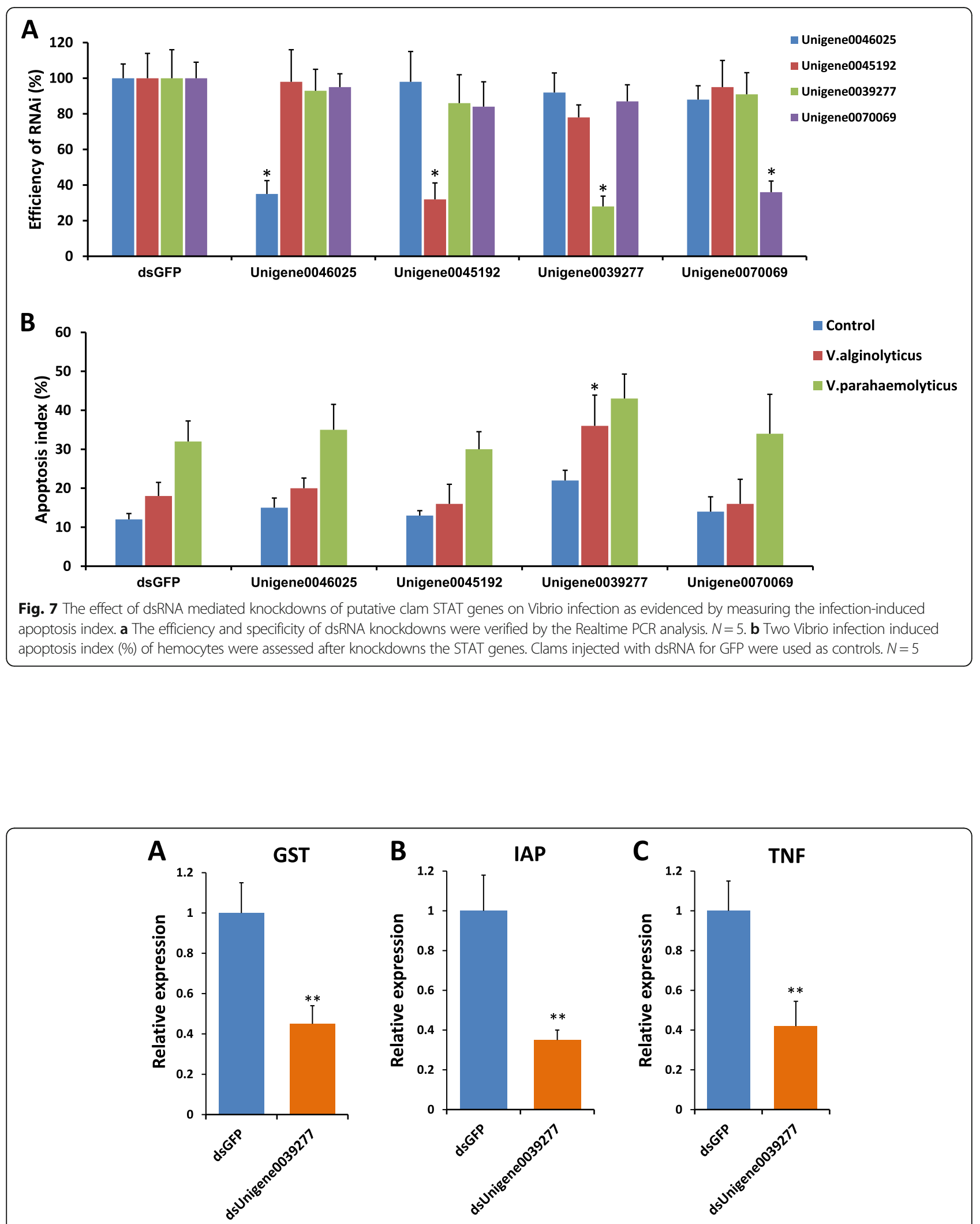

Fig. 8 The effect of knockdown STAT gene homolog, unigene0039277, on the expression of several candidates genes involved in clam defense. A clear reduction in the expression levels of (a) glutathione-S-transferase (GST), (b) inhibitor of apoptosis (IAP) and (c) tumor necrosis factor (TNF) was observed in ds Unigene0039277 clams. $N=5$ 


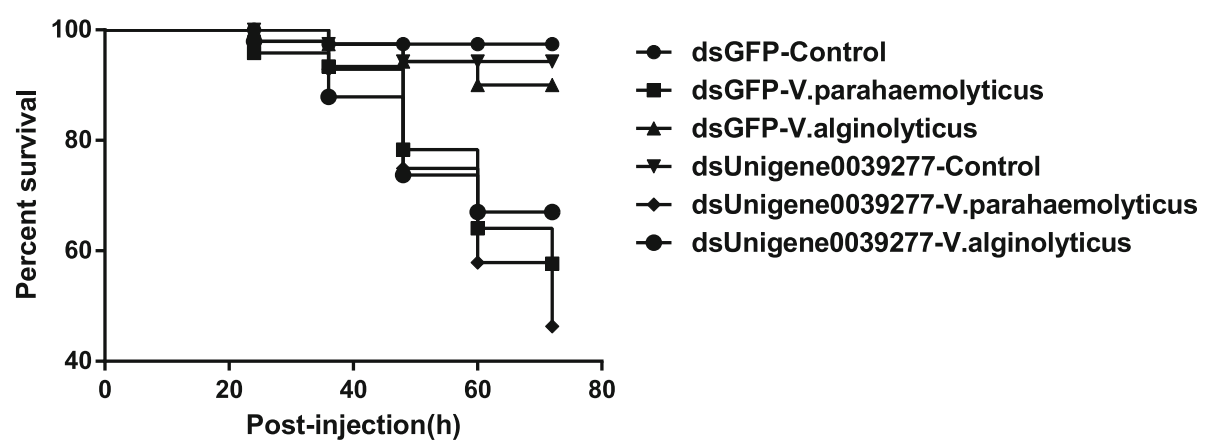

Fig. 9 Survival rate of Vibrio-infected clams treated with dsRNA against the STAT homolog, unigene0039277. dsGFP injected clams were used as controls. Uninfected dsGFP and dsUnigene0039277 clams were used for the purpose of comparisons. Each treatment or control contained $18-20$ individuals

alginolyticus, in surf clam $P$. undulate. As a consequence, a significantly high number of DEGs from the $V$. parahaemolyticus infected surf clams was observed for all the three major functional categories of GO database- biological process, cellular components and molecular functions. Most of these genes were enriched in GO terms as "cellular process", "metabolic process", "single organism process", "cell”, "cell parts", "organelle”, "macromolecular complex", "membrane", "membrane part", "binding”, "catalytic activity", "metabolic process", "response to stimulus", "establishment of localization" and "localization". A similar distribution of terms was observed for the $V$. alginolyticus infected clam DEGs mapped to GO database. In this regard, it can be mentioned here that, previous studies have generally identified similar GO slim terms associated with DEGs from different tissues of various bivalve species [9]. However, as compared to up-regulated ones, the number of downregulated genes was significantly higher in the $V$. parahaemolyticus infected group of surf clams. This was in contrast to $V$. alginolyticus where the higher numbers of mapped DEGs were associated with the up-regulated geneset. The VP down-regulated genes included significant number of candidates involved in clam immunity or immune related function.

Innate immunity is the major component of invertebrate immune system that is triggered by the recognition of conserved PAMPs present in the microbes by PRRs in the host [24]. Common PRRs include toll-like receptors (TLR), retinoic acid-inducible gene I [RIG-I]-like receptors (RLRs) and NACHT-leucine-rich repeat receptor (NLR) [24]. Pathogen recognition is followed by the binding of the pathogen with the cell membrane and the subsequent chemotactic migration of the immune cells like hemocytes towards invading pathogens. PAMP-PRR interaction activates intracellular signaling pathways, including adaptor molecules, kinases, transcription factors, trigger proinflammatory and antimicrobial effectors. Finally, the hemocytes phagocytose and kill these invaders by producing lysozymes, AMPs and toxic radicals. Phagocytosis is one of the most important defensive functions of hemocytes during which the immune cells recognize and eliminate non-self-components including invading and/or associating microorganisms [25]. During phagocytosis, phagosomes interact with the parts of the cell membrane and with the organelles including recycling endosomes, late endosomes and lysosomes [9]. The phagosomes get fused to the lysosomes forming phagolysosomes and release toxic products like reactive oxygen species, nitrogen species and proteins such as defensins and endopeptidases and exopeptidases, hydrolases and proteases which kill the pathogen and degrade them into fragments [9]. Additionally, immediately after pathogenic attack, the complement cascade is also activated which aids host defense [26].

In our study, 24 candidate genes were selected for qRT-PCR analyses based on their implication in the host-immune response towards Vibrio spp. and their differential expression observed in the clam hemocyte transcriptomic library. Most of the immune genes tested were highly induced under VA infection, indicating development of strong immune response in the host. However, a clear repression of several tested genes was observed in case of VP infection in comparison to VA. This repression of host immune genes might help explain the enhanced pathogenicity observed for VP. Among them, the Janus kinase (JAK)- signal transducers and activators of transcription (STAT) pathway is a pleiotropic signal transduction cascade that transduce a multitude of signals critical for cellular homeostatis, development and immunity [27]. Mechanistically, the JAKSTAT pathway is relatively simple consisting of three principal components- a membrane receptor for the extracellular signal, a JAK tyrosine kinase and STAT proteins [28]. The signaling pathway is activated by the binding of a variety of ligands including cytokines and growth regulators to the transmembrane receptor [29]. As a result, the receptor associated JAK proteins are 
activated through a conformational change which in turn phosphorylates latent STAT monomers leading to its dimerization, nuclear localization and DNA binding $[27,30-32]$. The effect of the pathway is finally manifested by alterations in the expression of JAK-STAT pathway target genes, providing a direct mechanism to translate an extracellular signal into a transcriptional response [29]. In addition the core components, the JAKSTAT pathway have other effector like adapters, pathway effectors and several pathway inhibitors (like suppressors of cytokine signaling (SOCS), protein inhibitors of activated STATs (PIAS), protein tyrosine phosphatases (PTPs) etc.). JAK-STAT is a classics signaling pathway that is evolutionarily conserved from vertebrates to lower organism inducing bivalves and other economically important marine organisms.

The JAK/STAT pathway is one of the major signaling cascades required for providing resistance against pathogenic attack, both in vertebrates and invertebrates. Although the pathway was initially discovered while researching antiviral mechanisms of interferons, it was later shown to play significant role against other pathogens as well [30]. Anti-viral role of JAK-STAT pathway has been widely reported in various organisms including Drosophila, mice and humans [30,33]. Loss of function mutation of JAK-STAT pathway leads to impaired antifungal defense in fruit fly Drosophila melanogaster [34, 35]. Particularly interesting is the finding that JAKSTAT pathway can provide resistance against Dengue virus in the disease carrying vector mosquitoes [35]. Anti-bacterial role of JAK/STAT pathway has also been widely reported with various effector genes identified to be regulated by the pathway $[36,37]$. JAK/STAT pathway has been consistently linked with antibacterial response in the gut in several organisms, where the pathway was demonstrated to induce production of anti-microbial peptides (AMPs) [37, 38]. There are relatively fewer studies reporting the role of JAK-STAT pathway in anti-fungal defense [38]; however several papers have demonstrated involvement of the pathway in resistance against the entomopathogenic fungus Beauveria bassiana in insects [38, 39]. Additionally, JAK-STAT pathway has also been implicated to play a role in encapsulation response in invertebrates, primarily via facilitating the differentiation of the hemocytes [40]. Encapsulation provides defense against parasites and foreign objects that invade the invertebrate circulatory system. The phenomenon is particularly prevalent amongst insects where JAK-STAT pathway is widely shown to induce encapsulation of parasitoid wasp eggs [40]. Thus, in additional to the multitude of physiological roles including development and homeostatic, JAK-STAT pathway plays a significant role in immune resistance against all kinds of pathogens and is a critical of component of host defense system.
In comparison to the wealth of information available for JAK-STAT pathway and its biological function in vertebrates and insects, relatively few studies have investigated the same in ecologically and economically important marine organisms. Although there are reports about the involvement of JAK-STAT pathway in antipathogen defense in various aquaculture organisms including shrimps and crabs [41, 42]. In mammals, four JAKs (JAK1, JAK2, JAK3, TYK2) and seven STATs (STAT1, STAT2, STAT3, STAT4, STAT5a, STAT5b, STAT6) have been reported [30]. In invertebrate species however, fewer homologs of JAK and STAT are usually reported, with most of the species harboring just one to two JAK and one STAT protein. Recent studies focus on JAK-STAT pathways in economically important mollusks including bivalves have identified the presence of JAK and STAT homologs as well as homologs of other important members of JAK-STAT pathway [18, 19]. Interestingly, like other organisms, a role of the pathway in anti-pathogenic defense has been reported in bivalves including mussel and oysters $[19,43]$.

In this study, JAK/SAT pathway plays a key role in bacterial clearance as evidenced by increased infection under inhibitor treatment in surf clams $P$. undulate. Knockdown of a particular putative STAT gene increased the virulence of $V$. alginolyticus, a bacterium generally perceived to be mildly pathogenic to $P$. undulate. Thus, we assume that VP, which is virulent to $P$. undulate, functions by suppressing the STAT homolog (unigene0039277). Interestingly, STAT3-dependent signal transduction has also been reported to be involved in immune response in whiteleg shrimp, Litopenaeus vannamei during Vibrio spp. infection. Increased mortality in Vibrio-infected Litopenaeus vannamei was reported due to inhibition of JAK/STAT pathway by cell death regulatory genes indicating that the latter was necessary for anti-bacterial defense [44]. However, the exact molecular mechanism by which JAK-STAT pathway provides resistance against Vibrio infection in surf clam remains to be elucidated. Interestingly, knockdown of the STAT homolog, unigene0039277, in clams resulted in repression of several other key immune genes like GST, IAP and TNF inspiring the idea that surf clam STAT indeed might be a key gene that regulate other immune genes in a systematic fashion. A thorough analysis of unigene0039277 knockdown clam is required to address these questions in the future.

\section{Conclusions}

The ability of a host organism to overcome a pathogenic attack depends on how successfully it can mount a defense in response to pathogenic attack. On the other hand, a pathogenic establishment requires overcoming or bypassing this host defense [45]. Pathogenic contact 
often results in induction in the expression of several key immune genes [45]. This induction of host immune genes has been found to be compromised in case of virulent pathogenic attack, which finally overcomes host defense to establish itself [45]. In our study, we observe the induction of several immunity related genes (as discussed above) in clams infected with $V$. alginolyticus. The expression of some of these genes remained low at a level almost comparable to the controls, in case of $V$. parahaemolyticus infection.

To the best of our knowledge, this is the first study on the investigation of transcriptome profile of the surf clams during the challenge by virulent Vibrio strain. The variation of expression of a large number of genes detected by RNA sequencing in our study provides a rich resource for studying the novel genes involved during Vibrio-challenge in surf clams. Comparative genomic analysis of $P$. undulate infected with two different Vibrio strains helped us demostrate key role of JAK/STAT pathway in clam defense and pathogen clearance. A specific putative STAT gene (unigene0039277) was found to provide enhanched resistance against Vibrio attack, and the suppression of this gene is presumed to be an important step in the establishment of infection by the virulent strain $V$. parahaemolyticus. However, the exact mechanism of repression of unigene0039277 or other immune genes remains unclear. Our findings might lead to the identification of therapeutic targets for infection minimization further helping us maintain ecological and economic stability of the surf clams.

\section{Methods}

\section{Collection and acclimatization of animals}

Surf clams used in this study were obtained from the local Fish Market of Xiamen, Fujian Province, China, and maintained at $18{ }^{\circ} \mathrm{C}-22^{\circ} \mathrm{C}$ in tanks with recirculating seawater for a 2 week prior to bacterial infection. Prior to the experiments, the clams were acclimatized to the aquarium conditions for 2 week. The clams were fed twice daily with the marine algae, Tetraselmis suecica and Isochrysis galbana.

\section{Pathogenic challenge and survival rate}

The clams were injected in the muscles with $100 \mu \mathrm{l}$ of either $V$. alginolyticus $\left(1 \times 10^{7} \mathrm{CFU} / \mathrm{ml}\right)$ or $V$. parahaemolyticus $\left(1 \times 10^{7} \mathrm{CFU} / \mathrm{ml}\right)$ (These two Vibrio strains were graciously provided by Prof. Hu at South China Sea Institute of Oceanology, Chinese Academy of Sciences). Clams injected with $100 \mu \mathrm{l}$ of phosphate buffered saline (PBS) were taken as controls [46]. Then the clams were returned to the tanks and maintained $18{ }^{\circ} \mathrm{C}-22^{\circ} \mathrm{C}$ until sampling. To measure the rate of survival of the clams, they were taken out of the tanks at definite time intervals of $24 \mathrm{~h}, 48 \mathrm{~h}, 60 \mathrm{~h}$ and $72 \mathrm{~h}$ post-infection and were examined for the presence of dead ones. The percentage of the surviving clams was calculated at each time interval for all the three groups.

\section{RNA isolation}

Hemolymph was withdrawn from the adductor muscle of the control and the two Vibrio infected groups of clams $24 \mathrm{~h}$ post pathogenic injection, using a $0.5 \mathrm{~mm}$ diameter (25G) disposable needle. In total, 300 clams representing five biological replicates of bacterial challenge (Three treatments $\times$ five time points $\times$ five biological replicates $\times$ four clams per sample) were used for the expression analysis and stored at $-80^{\circ} \mathrm{C}$ for RNA isolation. For RNA isolation, hemolymph was pooled from 20 individuals from each group. The experiment was repeated in triplicates. Briefly, the hemolymph was centrifuged at $3000 \mathrm{~g}$ for $10 \mathrm{~min}$ at $4{ }^{\circ} \mathrm{C}$. The pellet was suspended in $250 \mu \mathrm{l}$ of TRIzol (Invitrogen). Total RNA was isolated from each sample following the manufacturer's protocols; followed by RNA purification with the RNeasy Mini kit (Qiagen) after treating with RNAasefree DNase I (NEB). The concentration and purity of isolated RNA was measured at $260 \mathrm{~nm} / 280 \mathrm{~nm}$ (A260/ A280) using spectrophotometer (Thermo Scientific). The RNA integrity was examined on Agilent 2100 Bioanalyser RNA Nano Chip (Agilent Technologies, USA) and by running on agarose gel electrophoresis.

\section{Illumina RNA-seq library preparation}

To characterize the immune response among $V$. parahaemolyticus-infected groups of clams and to compare it with the control and $V$. alginolyticus-infected group, quantitative gene expression analysis for all the three groups of clams was performed using the Illumina RNAseq technology on HiSeq 2000 platform [47, 48].

The extracted mRNA was converted to cDNA using SuperScript II reverse transcriptase (Invitrogen). cDNA was ligated to Illumina TruSeq RNA multiplex adaptor sequences using the TruSeq RNA sample prep kit (Illumina). Size-selected cDNA fragments of $200 \mathrm{bp}$ ( $\pm 25 \mathrm{bp}$ ) excised from a $2 \%$ agarose gel were amplified using Illumina PCR primers for paired-end reads (Illumina), and 15 cycles of the PCR programme comprising $98^{\circ} \mathrm{C}$ for $30 \mathrm{~s}, 98^{\circ} \mathrm{C}$ for $10 \mathrm{~s}, 65^{\circ} \mathrm{C}$ for $30 \mathrm{~s}$ and $72^{\circ} \mathrm{C}$ for $30 \mathrm{~s}$, followed by an extension step of $5 \mathrm{~min}$ at $72^{\circ} \mathrm{C}$. After quantified by TBS380, two RNAseq libraries were sequenced in single lane on an Illumina Hiseq Xten sequencer (Illumina, San Diego, CA) for $2 \times 150$ bp pairedend reads.

\section{Data processing}

Quality of reads was visualized with FastQC (http:// www.bioinformatics.bbsrc.ac.uk/projects/fastqc). Initial removal of low-quality reads and multiplex index 
adaptor sequences (Illumina) was performed with edgeR [49], setting the quality threshold to minimum Phred score of 20/30. The rRNA sequence contamination, empty reads and sequences with copy number 1 were also removed.

The clean reads with quality scores greater than 20/30 $\left(\mathrm{Q}_{20 / 30}\right)$ were assembled and mapped to the reference transcriptome of surf clam using edgeR; allowing only 1 or $2 \mathrm{bp}$ mismatch [6]. For functional annotation, the differentially expressed gene (DEG) that mapped to only one gene in the reference database were taken and normalized to RPKM (Reads Per Kb per Million reads). The high quality short reads were submitted at the National Centre for Biological Information (NCBI) Short Read Archive (SRA; http://www.ncbi.nlm.nih.gov/sra/) under the accession numbers PRJNA560440.

\section{Gene ontology (GO) analyses}

For GO analysis, the DEGs obtained from Illumina platform were mapped to terms in $\mathrm{GO}$ database version $\mathrm{GO}$ slim (http://www.geneontology.org) using Amigo (http:// amigo.geneontology.org/) software. GO based functional analysis gave us a broad overview of the ontology content with respect to biological processes, cellular components and molecular functions [6, 9, 10, 47]. Default parameters were used to execute the analysis and the biological process ontology level 2 was selected [2, 13]. The up- and down-regulated genes from the annotated genes in GO database were identified using DAVID [47].

\section{Quantitative real time PCR (qRT-PCR)}

cDNA was synthesized from $1 \mu \mathrm{g}$ RNA using PrimeScript $^{\text {th }}$ RT Reagent Kit Ver.2.0 (TaKaRa, Japan). The qRT-PCR reactions were performed in triplicate on a Light Cycler 480 platform (Roche) in a volume of $20 \mu \mathrm{l}$ using $1 \mu \mathrm{L}$ of diluted cDNA (1:10), $0.4 \mu \mathrm{L}$ of each of the forward and reverse primers $(10 \mathrm{mM})$ and $10 \mathrm{~mL}$ of $2 \times$ Master Mix (Roche, USA) with the cycling conditions as follows: $95^{\circ} \mathrm{C}$ for $5 \mathrm{~min}$, followed by 40 cycles of $94{ }^{\circ} \mathrm{C}$ for $5 \mathrm{~s}, 60^{\circ} \mathrm{C}$ for $31 \mathrm{~s}[6,50]$. Beta actin was used as an internal control. The list of the genes chosen and the primers sequences for qRT-PCR are provided in Table 3.

\section{Measurement of bacterial count}

The clams were injected with $5 \mathrm{mg} / \mathrm{kg}$ and $20 \mathrm{mg} / \mathrm{kg}$ of methotrexate (Sigma) and ruxolitinib (Sigma) respectively in their adductor muscles; followed by infection with $100 \mu \mathrm{l}$ of $1 \times 10^{7} \mathrm{CFU} / \mathrm{ml}$ of either $V$. alginolyticus or $V$. parahaemolyticus. Clams treated with dimethyl sulfoxide (DMSO) were used as control. Then the clams were returned to the tanks and maintained at $25^{\circ} \mathrm{C}$ until sampling. The hemolymph was withdrawn from their adductor muscles after $24 \mathrm{~h}$ and plated onto TCBS media and incubated for $12 \mathrm{~h}$ at $37^{\circ} \mathrm{C}$ and were observed for the growth of Vibrio spp. The positive colonies formed on the plates were counted and compared with control.

\section{Measurement of apoptosis index}

For apoptotic index, the percentage of apoptotic hemocytes were analyzed in a flow cytometry (BD FACS Calibur) using fluorescence intensity based (photometric) assay targeting the hallmark of apoptosis (TUNEL (Terminal Deoxynucleotide Transferase dUTP Nick End Labeling) assay for detection of DNA fragmentation, the Annexin V assay for surface phosphatidylserine (PS) exposure, and fluorogenic caspase substrates to detect caspase activation) [50]. Approximately $10^{5}$ hemocytes were collected for apoptotic analysis, and total of 10,000 cells were obtained to detect in the flow cytometry. Finally, the result was conducted by FlowJo software.

\section{dsRNA-mediated gene silencing}

dsRNA synthesis was performed using the MEGAscript T7 Transcription Kit (Life Technologies, USA) following the protocol. $50 \mu \mathrm{g}$ of dsRNA was microinjected into the adductor muscles of the oyster to knockdown the expression of target genes. Then the clams were infected with Vibrio spp. as described before. Apoptosis indices and survival rate of the clams were measured. The relative expression of inflammatory molecules including glutathione-S-transferase (GST), apoptosis inhibitors (IAP) and tumor necrosis factor (TNF) were measured using qRT-PCR of mRNA isolated from these clams. The primers used to synthesize dsRNA are given in Table 3. Green fluorescent protein (GFP) was used as the internal control.

\section{Statistical analysis}

One way ANOVA was used to analyze the mean differences among samples. Pair-wise $t$-test was then applied to compare gene expression levels between the two surf clam populations. All statistical analyses (avo functions and pairwise t-test functions)) were conducted in the $\mathrm{R}$ computation environment (http://www.r-project.org) [47]. Pvalues $\leq 0.05$ was considered statistically significant. The correlation statistics was performed and Pearson correlation coefficient (R) was calculated at $P$ value $<0.0001$.

\footnotetext{
Abbreviations

AMPs: Antimicrobial peptides; DEGs: Differentially expressed genes:

FDR: False discovery rate; GFP: Green fluorescent protein; GO: Gene ontology GST: Glutathione-S-transferase; IAP: Apoptosis inhibitors; NLR: NACHT-leucinerich repeat receptor; PAMPs: Pathogen-associated molecular patterns; PIAS: Protein inhibitors of activated STATs; PRRs: Pattern recognition receptors; PTPs: Protein tyrosine phosphatases; RLRs: Retinoic acid-inducible gene I -like receptors; RPKM: Reads Per Kb per Million reads; SOCS: Suppressors of cytokine signaling; STAT: Signal transducers and activators of transcription; TLR: Toll-like receptors; TNF: Tumor necrosis factor; TUNEL: Terminal Deoxynucleotide Transferase dUTP Nick End Labeling; VA: Vibrio alginolyticus; VP: Vibrio parahaemolyticus
} 


\section{Acknowledgements}

We thank Xuehua Xiao, Jingtao Liang and Min Zhang at Foshan Center for Disease Control and Prevention for their suggestions and support.

\section{Authors' contributions}

Conception and design of the work, MY, YZ; analysis, LZ, XW, MW, MQ and WF; Drafting the manuscript, MY, YZ; Editing and revising the manuscript, YZ. All authors have read and approved the final manuscript.

\section{Funding}

This work was financially supported by the Guangdong Natural Science Funds for Distinguished Young Scholars (No.2015A030306003), the National Science Foundation of China (No. 31572640), the Guangdong Special Support Program of Youth Scientific and Technological Innovation (No. 2015TQ01N139), Institution of South China Sea Ecology and Environmental Engineering, Chinese Academy of Sciences (No.ISEE2018PY03), Science and Technology Planning Project of Guangzhou, China (2017B030314052, 201707010177). The funding bodies played no role in the design of the study and collection, analysis, and interpretation of data and in writing the manuscript.

\section{Availability of data and materials}

The high quality short reads were submitted at the National Centre for Biological Information (NCBI) Short Read Archive (SRA; http://www.ncbi.nlm. nih.gov/sra/) under the accession numbers PRJNA560440. Software input and output files generated in study is available from corresponding author.

\section{Ethics approval and consent to participate}

Not applicable.

\section{Consent for publication}

Not applicable.

\section{Competing interests}

The authors declare that they have no competing interests.

\section{Author details}

'Department of Food Science, Foshan Polytechnic, Foshan 528137, China ${ }^{2}$ Zhejiang Marine Development Research Institute, Zhoushan 316100, People's Republic of China. ${ }^{3}$ CAS Key Laboratory of Tropical Marine Bio-resources and Ecology, Guangdong Provincial Key Laboratory of Applied Marine Biology, South China Sea Institute of Oceanology, Chinese Academy of Science, 164 West Xingang Road, Guangzhou 510301, China. ${ }^{4}$ Innovation Academy of South China Sea Ecology and Environmental Engineering (ISEE), Chinese Academy of Sciences, Beijing 100864, China.

Received: 3 September 2019 Accepted: 28 November 2019 Published online: 17 December 2019

\section{References}

1. Leethochavalit S, Chalermwat K, Upatham ES, Choi KS, Sawangwong P, Kruatrachue M. Occurrence of Perkinsus sp. in undulated surf clams Paphia undulata from the Gulf of Thailand. Dis Aquat Org. 2004;60(2):165-71.

2. Moreira R, Milan M, Balseiro P, Romero A, Babbucci M, Fiqueras A, Bargellon L, Novoa B. Gene expression profile analysis of Manila clam (Ruditapes philippinarum) hemocytes after a Vibrio alginolyticus challenge using an immune-enriched oligo-microarray. BMC Genomics. 2014;15:267.

3. Bernal-Hernandez YY, Medina-Diaz IM, Robledo-Marenco ML, VelazquezFernandez JB, Giron-Perez MI, Ortega-Cervantes L, Maldonado-Vazquez WA, Rojas-Garcia AE. Acetylcholinesterase and metallothionein in oysters (Crassostrea corteziensis) from a subtropical Mexican Pacific estuary. Ecotoxicology. 2010;19(4):819-25

4. Galloway TS, Depledge MH. Immunotoxicity in invertebrates: measurement and ecotoxicological relevance. Ecotoxicology. 2001;10(1):5-23.

5. Maldonado-Aguayo W, Lafarga-De la Cruz F, Gallardo-Escarate C. Identification and expression of antioxidant and immune defense genes in the surf clam Mesodesma donacium challenged with Vibrio anguillarum. Mar Genomics. 2015;19:65-73.

6. Gong L, Chen X, Liu C, Jin F, Hu Q. Gene expression profile of Bombyx mori hemocyte under the stress of destruxin a. PLoS One. 2014;9(5):e96170.
7. Yu M, Yang S, Sun H, Xia Q. CD63 promotes Hemocyte-mediated phagocytosis in the clam, Paphia undulata. J Immunol Res. 2016;2016: 7893490 .

8. Girón-Pérez. Relationships between innate immunity in bivalve molluscs and environmental pollution. Invert Surviv J. 2010;7(2):149.

9. Tanguy M, McKenna P, Gauthier-Clerc S, Pellerin J, Danger JM, Siah A. Sequence analysis of a normalized cDNA library of Mytilus edulis hemocytes exposed to Vibrio splendidus LGP32 strain. Results Immunol. 2013;3:40-50.

10. Xue S, Liu Y, Zhang Y, Sun Y, Geng X, Sun J. Sequencing and de novo analysis of the hemocytes transcriptome in Litopenaeus vannamei response to white spot syndrome virus infection. PLoS One. 2013;8(10):e76718.

11. Wang K, del Castillo C, Corre E, Pales Espinosa E, Allam B. Clam focal and systemic immune responses to QPX infection revealed by RNA-seq technology. BMC Genomics. 2016;17:146.

12. Yu M, Chen J, Bao Y, Li J. Genomic analysis of NF-kappaB signaling pathway reveals its complexity in Crassostrea gigas. Fish Shellfish Immunol. 2018;72: $510-8$.

13. Patnaik BB, Wang TH, Kang SW, Hwang HJ, Park SY, Park EB, Chung JM, Song DK, Kim C, Kim S, et al. Sequencing, De novo assembly, and annotation of the transcriptome of the endangered freshwater pearl bivalve, Cristaria plicata, provides novel insights into functional genes and marker discovery. PLoS One. 2016;11(2):e0148622.

14. Wang Z, Wang B, Chen G, Jian J, Lu Y, Xu Y, Wu Z. Transcriptome analysis of the pearl oyster (Pinctada fucata) hemocytes in response to Vibrio alginolyticus infection. Gene. 2016;575(2 Pt 2):421-8.

15. Pan B, Ren Y, Gao J, Gao H. De novo RNA-Seq analysis of the venus clam, Cyclina sinensis, and the identification of immune-related genes. PLoS One. 2015:10(4):e0123296.

16. Maldonado-Aguayo W, Nunez-Acuna G, Valenzuela-Munoz V, ChavezMardones J, Gallardo-Escarate C. Molecular characterization of two kazal-type serine proteinase inhibitor genes in the surf clam Mesodesma donacium exposed to Vibrio anguillarum. Fish Shellfish Immunol. 2013;34(6):1448-54.

17. Fang $Y$, Yang $H$, Liu B, Zhang L. Transcriptional response of lysozyme, metallothionein, and superoxide dismutase to combined exposure to heavy metals and bacteria in Mactra veneriformis. Comp Biochem Physiol C Toxicol Pharmacol. 2013:157(1):54-62.

18. Li J, Zhang Y, Zhang Y, Liu Y, Xiang Z, Qu F, Yu Z. Cloning and characterization of three suppressors of cytokine signaling (SOCS) genes from the Pacific oyster, Crassostrea gigas. Fish Shellfish Immunol. 2015; 44(2):525-32.

19. Liu WG, Huang XD, Wang Q, Zhao M, Wu SZ, He MX. Gene cloning and function analysis of cytokine-induced suppressor of cytokine signaling (SOCS) from pearl oyster Pinctada fucata. Fish Shellfish Immunol. 2013;34(3): 849-54.

20. Barozzi F, Di Sansebastiano GP, Sabella E, Aprile A, Piro G, De Bellis L, Nutricati E. Glutathione S-transferase related detoxification processes are correlated with receptor-mediated vacuolar sorting mechanisms. Plant Cell Rep. 2017;36(9):1361-73.

21. Roncalli V, Cieslak MC, Passamaneck Y, Christie AE, Lenz PH. Glutathione STransferase (GST) gene diversity in the crustacean Calanus finmarchicus-contributors to cellular detoxification. PLoS One. 2015:10(5):e0123322.

22. Deveraux QL, Reed JC. IAP family proteins--suppressors of apoptosis. Genes Dev. 1999;13(3):239-52.

23. Kocab AJ, Veloso A, Paulsen MT, Ljungman M, Duckett CS. Effects of physiological and synthetic IAP antagonism on C-IAP-dependent signaling. Oncogene. 2015;34(43):5472-81.

24. Zhang Y, Li J, Yu F, He X, Yu Z. Allograft inflammatory factor-1 stimulates hemocyte immune activation by enhancing phagocytosis and expression of inflammatory cytokines in Crassostrea gigas. Fish Shellfish Immunol. 2013; 34(5):1071-7.

25. Tame A, Yoshida T, Ohishi K, Maruyama T. Phagocytic activities of hemocytes from the deep-sea symbiotic mussels Bathymodiolus japonicus, B. platifrons, and B. septemdierum. Fish Shellfish Immunol. 2015;45(1):146-56.

26. Wang $L$, Wang $L$, Zhang $H$, Zhou Z, Siva VS, Song L. A C1q domain containing protein from scallop Chlamys farreri serving as pattern recognition receptor with heat-aggregated IgG binding activity. PLoS One. 2012;7(8):e43289.

27. Stark GR, Darnell JE Jr. The JAK-STAT pathway at twenty. Immunity. 2012; 36(4):503-14.

28. Aaronson DS, Horvath CM. A road map for those who don't know JAKSTAT. Science. 2002;296(5573):1653-5. 
29. Rawlings JS, Rosler KM, Harrison DA. The JAK/STAT signaling pathway. J Cell Sci. 2004;117(Pt 8):1281-3.

30. Villarino AV, Kanno Y, Ferdinand JR, O'Shea JJ. Mechanisms of Jak/STAT signaling in immunity and disease. J Immunol. 2015;194(1):21-7.

31. Gorissen M, de Vrieze E, Flik G, Huising MO. STAT genes display differential evolutionary rates that correlate with their roles in the endocrine and immune system. J Endocrinol. 2011;209(2):175-84.

32. Brooks AJ, Dai W, O'Mara ML, Abankwa D, Chhabra Y, Pelekanos RA, Gardon O, Tunny KA, Blucher KM, Morton CJ, et al. Mechanism of activation of protein kinase JAK2 by the growth hormone receptor. Science. 2014; 344(6185):1249783.

33. Agaisse $\mathrm{H}$, Perrimon $\mathrm{N}$. The roles of JAK/STAT signaling in Drosophila immune responses. Immunol Rev. 2004;198(1):72-82.

34. Myllymaki H, Ramet M. JAK/STAT pathway in Drosophila immunity. Scand J Immunol. 2014;79(6):377-85.

35. Souza-Neto JA, Sim S, Dimopoulos G. An evolutionary conserved function of the JAK-STAT pathway in anti-dengue defense. Proc Natl Acad Sci U S A. 2009;106(42):17841-6.

36. Godshall CJ, Lentsch AB, Peyton JC, Scott MJ, Cheadle WG. STAT4 is required for antibacterial defense but enhances mortality during polymicrobial sepsis. Clin Diagn Lab Immunol. 2001;8(6):1044-8.

37. Buchon N, Broderick NA, Poidevin M, Pradervand S, Lemaitre B. Drosophila intestinal response to bacterial infection: activation of host defense and stem cell proliferation. Cell Host Microbe. 2009;5(2):200-11.

38. Dong Y, Morton JC Jr, Ramirez JL, Souza-Neto JA, Dimopoulos G. The entomopathogenic fungus Beauveria bassiana activate toll and JAK-STAT pathway-controlled effector genes and anti-dengue activity in Aedes aegypti. Insect Biochem Mol Biol. 2012;42(2):126-32.

39. Geng T, Lv DD, Huang YX, Hou CX, Qin GX, Guo XJ. JAK/STAT signaling pathway-mediated immune response in silkworm (Bombyx mori) challenged by Beauveria bassiana. Gene. 2016;595(1):69-76.

40. Yang H, Kronhamn J, Ekstrom JO, Korkut GG, Hultmark D. JAKJSTAT signaling in Drosophila muscles controls the cellular immune response against parasitoid infection. EMBO Rep. 2015;16(12):1664-72.

41. Okugawa S, Mekata T, Inada M, Kihara K, Shiki A, Kannabiran K, Kono T, Sakai M, Yoshida T, Itami T, et al. The SOCS and STAT from JAK/STAT signaling pathway of kuruma shrimp Marsupenaeus japonicus: molecular cloning, characterization and expression analysis. Mol Cell Probes. 2013;27(1):6-14.

42. Verbruggen B, Bickley LK, Santos EM, Tyler CR, Stentiford GD, Bateman KS, van Aerle R. De novo assembly of the Carcinus maenas transcriptome and characterization of innate immune system pathways. BMC Genomics. 2015;16:458.

43. Dai YJ, Hui KM, Zhang YH, Liu Y, Wang YQ, Zhao LJ, Lin L, Chai LQ, Wei S, Lan JF. Three STATs are involved in the regulation of the expression of antimicrobial peptides in the triangle sail mussel, Hyriopsis cumingii. Fish Shellfish Immunol. 2017;63:181-8.

44. Peng T, Gu MM, Zhao CS, Wang WN, Huang MZ, Xie CY, Xiao YC, Cha GH, Liu Y. The GRIM-19 plays a vital role in shrimps' responses to Vibrio alginolyticus. Fish Shellfish Immunol. 2016:49:34-44.

45. Jr CAJ, Travers P, Walport M, MJJGS S. Pathogens have evolved various means of evading or subverting normal host defenses. In: Immunobiology NCBI Bookshelf; 2001.

46. Yu M, Zhang Y, Tang $X$, Ren J, Zhang Y. The first mollusk spatzle homolog gene in the clam, Paphia undulate. Fish Shellfish Immunol. 2015;47(2):712-6.

47. Xie C, Chen Y, Sun W, Ding J, Zhou L, Wang S, Wang S, Zhang Y, Zhu D, Wen $X$, et al. Transcriptome and expression profiling analysis of the hemocytes reveals a large number of immune-related genes in mud crab Scylla paramamosain during Vibrio parahaemolyticus infection. PLoS One. 2014;9(12):e114500.

48. Saha TT, Shin SW, Dou W, Roy S, Zhao B, Hou Y, Wang XL, Zou Z, Girke T, Raikhel AS. Hairy and Groucho mediate the action of juvenile hormone receptor Methoprene-tolerant in gene repression. Proc Natl Acad Sci U S A. 2016;113(6):E735-43.

49. Nookaew I, Papini M, Pornputtapong N, Scalcinati G, Fagerberg L, Uhlen M, Nielsen J. A comprehensive comparison of RNA-Seq-based transcriptome analysis from reads to differential gene expression and cross-comparison with microarrays: a case study in Saccharomyces cerevisiae. Nucleic Acids Res. 2012;40(20):10084-97.

50. Hegaret H, da Silva PM, Wikfors GH, Lambert C, De Bettignies T, Shumway SE, Soudant P. Hemocyte responses of Manila clams, Ruditapes philippinarum, with varying parasite, Perkinsus olseni, severity to toxic-algal exposures. Aquat Toxicol. 2007;84(4):469-79.

\section{Publisher's Note}

Springer Nature remains neutral with regard to jurisdictional claims in published maps and institutional affiliations.

\section{Ready to submit your research? Choose BMC and benefit from:}

- fast, convenient online submission

- thorough peer review by experienced researchers in your field

- rapid publication on acceptance

- support for research data, including large and complex data types

- gold Open Access which fosters wider collaboration and increased citations

- maximum visibility for your research: over $100 \mathrm{M}$ website views per year

At BMC, research is always in progress.

Learn more biomedcentral.com/submissions 